\title{
The Stanford Flood
}

\author{
In November 1978 the Stanford University Libraries, Stanford, California, \\ experienced a significant flood in a basement stack. This article describes \\ the events from the flood to the start of freeze-drying operations.
}

T HE GREEN LIBRARY at Stanford University, Stanford, California, houses the general research collections for the university, particularly in the humanities and social sciences. The original "main" library (now known as the Cecil H. Green Library), built in 1919, ran out of space in the 1950s. A number of efforts to relieve space problems, undertaken over the intervening years, included the construction of a large basement shelving area under the nearby J. Henry Meyer Undergraduate Library. This basement stack facility contains some 400,000 volumes of the central research collections on two levels of metal-tiered stack construction. There is currently under construction a major addition to the Green Library that will connect by underground stack space the old central library with the Meyer basement.

At 2:51 a.m. on Saturday, November 4, 1978, an eight-inch sprinkler main burst. ${ }^{1}$ The rupture site was outside the Meyer building, perhaps twenty feet from the nearest exterior wall. Water rushing from a five-foot-long crack quickly filled a substantial excavated area associated with the construction in progress and found its way through a number of holes in the exterior wall of the building that had been core drilled in anticipation of the installation of several drains and other pipes whose relocation was required by the Green Library construction effort.

Philip D. Leighton is building projects manager, Stanford University Libraries. The author gratefully acknowledges the efforts of other members of the disaster team, particularly Ralph W. Hansen, chief of the Acquisition Department and coordinator of the restoration project, and Sally Buchanan, restoration project assistant.
Water entered the upper level of the tiered stack and spread out over an area of about 5,000 square feet. The floor's construction, of steel channels, permitted the water to drip to the floor below. Most dripping occurred where the channel members butt end to end at the structural support. In a tiered stack, of course, structural support is provided by shelving uprights on lower levels. Thus, while very few items were totally immersed, the persistent dripping managed to soak to varying degrees more than 46,000 volumes.

Fortunately, as this event involved a fire-related system, a fire alarm was set off by the line pressure drop. Stanford's plumbing crew happened to be on campus working on another leak; we were again fortunate that they responded quickly to a call from the fire department. The water was turned off twenty minutes after the rupture.

The first impression of the flood site was devastating. As the water traversed the twenty feet to the basement wall, it carried with it very fine particles of soil, which were deposited in a layer over the floor on both levels. This silt eventually found its way into the sump pumps, causing them to be "mud bound," a condition that was aggravated as the cleanup crew initially dumped their buckets at the sumps. Many books were swollen to the point that they were jammed into the shelves; a few had popped off the shelves. It appeared that there were never more than a few inches of water standing on the floor of either level; clearly the dripping was the major source of damage. For four or five hours it was almost like a heavy rain on the lower level.

Most of the lights continued to function, but the freight elevator pit was flooded, causing minor damage to some equipment. 
Power was maintained for the initial cleanup operations by Stanford's janitorial contractor using floor squeegees, mops, and large wet-or-dry vacuums. Most of the mud and water was cleared by 8:00 a.m.

\section{First PlanNing}

By 5:30 a.m., a small group of administrators were informed of a meeting to be held at 6:00 a.m. in the library director's office. The individuals represented those concerned for security and physical operations, those representing our greatest knowledge of preservation techniques, and those actually responsible for the collections and their service and development. The assistant director for administrative services, the first library staff member summoned to the scene, gave a verbal account of what he had seen on his visit to the flood site. While he did not know the extent of the flooded area, the description of what he had seen was grim.

The following outline presents briefly, in rough chronological order, the events of the first planning session:

- About a dozen photocopies of Peter Waters' booklet Procedures for Salvage of Water-damaged Library Materials were prepared and read. ${ }^{2}$

- The decision was made to freeze the materials as quickly as possible.

- A quick assessment of the extent of damage was scheduled.

- By phone, a request was initiated to Stanford's service operations to turn on all the building air-handling systems to maximize the circulation of cool, fresh air so as to reduce the ambient humidity as quickly as possible.

- The assistant director for administrative services was appointed as coordinator for the initial rescue effort.

- It was decided to keep a photographic record of the general procedure. Film, coffee, and doughnuts were ordered as soon as stores were open.

After some delay while cleaning progressed, the group entered the Meyer basement for the first time to assess the extent of damage. The cleaning crew was still fully involved; mud and water were still on the floor. Probably the greatest hazard to personnel at this point was the icelike slickness of the silt and water $\sim$ A quick tour showed that the entire basement was not flooded, a fact that was welcome news indeed.

The group dispersed to assigned areas to estimate the extent of flood damage by recording on stack shelving plans the individual shelving sections that were wet. This involved feeling the tops of books for moisture (it is a crude test, because books may feel dry and still contain 30 percent moisture) and to ascertain how far the water had migrated. This gave the number of books involved so that the magnitude of the required salvage project could be estimated. Access to an Aqua-Boy, an instrument for measuring moisture content, would have been useful in this phase.

The survey included student carrels, three storage rooms, and the circulation staff quarters.

At a second meeting further decisions evolved from the assessment of the situation. Again, in outline form, the events were:

- It was estimated that 37,000 to 40,000 volumes were in the area soaked. We later found the number to be higher.

- A goal was set to remove and freeze all water-damaged materials within forty-eight hours in order to minimize the possibility of mold growth.

- All material on the affected shelving would be removed for freezing. Although some might not be wet, there was no time for selective decisions on individual items.

- Staff members were assigned tasks of seeking workers, supervising work crews, obtaining supplies, ensuring that the elevators worked, lining up trucks and pallet movers, arranging for freezer service, ordering lunch, and clearing logjams.

- The director's office was designated the weekend communication center.

News of the flood was spreading, and by the time of the second meeting (about 10:00 a.m.) the group of interested or concerned people included Stanford's director of risk management, a member of the construction management office (the contractor involved with the current construction project was quick to respond as well), a representative of the security office, the plant services director, Stanford's stores manager, and the director of Stanford's news services. All 
were anxious to help in any way they could.

It was clear that nearly anything needed, from two sizes of cardboard boxes to volunteers, could be provided quickly with the help of these people. We were concerned about being overwhelmed with volunteers (there were probably 90,000 football fans on campus to witness the Stanford/USC game that afternoon); fortunately the only "need" expressed in the news releases was for freezer space. ${ }^{3}$ As expected, the response was impressive, but it turned out to be unnecessary, as we had taken the preplanning step to arrange for the possibility of using a local freezer, Peninsula Dairy. Although this particular freezer was full, the firm was able to refer us to another freezer facility, Modern Ice and Cold Storage in San Jose (about twenty-five miles away), which would take anything we had. Peninsula Dairy did provide a freezer truck and plastic crates, which were useful in the removal effort.

Beyond wanting to know what kind of assistance was desired, the news media also wanted to know all the details of the event, its cause and extent, and the value of the affected items. Almost none of these questions could be answered accurately. Because of the implied liability questions, and indeed a general lack of information, little could be said about the cause other than the obvious. We had some measure of the extent of damage in terms of area covered, but we had little knowledge of how many items would require careful restoration, or the number of items that could be placed directly on the shelves after drying, or anything between. Figures on the cost implications ran generally from one to three million dollars for the estimated forty thousand volumes involved. (It was agreed the University News Service would act as the official news source. Later, one of the library staff was appointed as the library's news representative to whom questions were to be directed.)

The risk manager's advice was clear: prudent action must be taken in order to minimize loss even though liability, costs, financing, or other factors were not re-

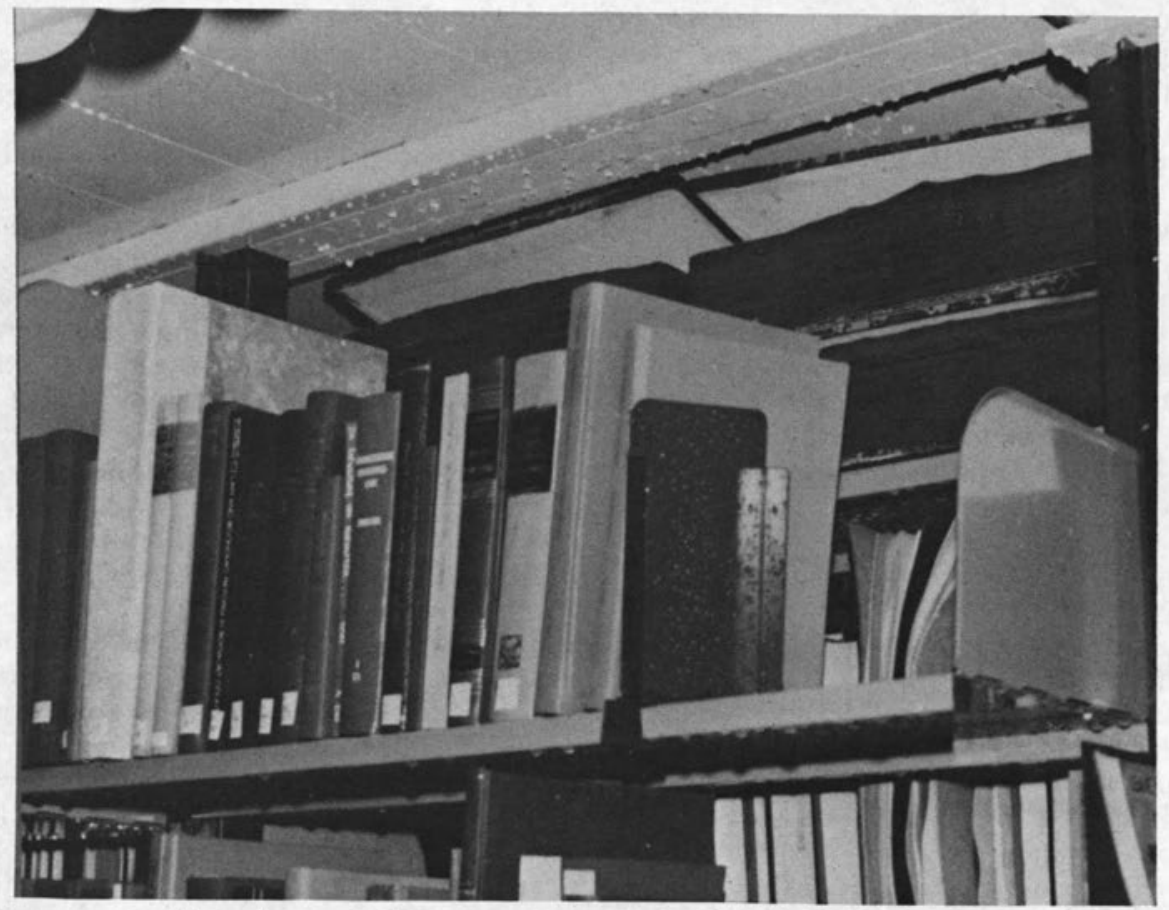

Even after several hours water continues to drip on the books below. 
solved. Clearly we felt that removal and freezing of the materials was proper, prudent action.

\section{ACTION}

By about 11:00 a.m. the gears were set in motion, but it would be another three hours before we would be in full operation. There were supplies to obtain, including note pads, marking pens, plastic bags, freezer paper, wrapping tape, milk crates, and cardboard boxes. Equipment needs included a fleet of book trucks, tape machines, a roll paper cutter, worktables, pallets, pallet movers, forklifts, and freezer trucks. There were elevators to repair and a few lights to activate, and the final cleaning was still in process. As all water to the library was turned off, we had half a dozen portable toilets set up outside the building. ${ }^{4}$

Our initial estimate of 3,000 cartons needed was low; we actually used about 4,500 cartons of various descriptions. Freezer paper was picked up at Crown Zellerbach in large rolls (forty 300-yard rolls); what was not used was returned. By final count, 159 pallets were required. A small quantity of plastic bags in several sizes were purchased at local stores, mostly for students' papers that had been left on some carrels.

As volunteers arrived, they were grouped into small work crews prior to entering the flood area. Separate crews were established for folding and taping boxes, cutting freezer paper into sheets (typically about twelve to eighteen inches long), moving supplies to the packing crews, packing, loading packed boxes onto book trucks and moving them to the two passenger elevators, moving the loaded trucks from the elevator on the ground floor and placing the packed boxes on pallets, returning empty book trucks to the loading crews in the basement, and moving the palletized boxes (with the boxes stacked three to four feet high) into freezer trucks. Some of the crews were fairly loose-knit, with people moving from one function to another as need required. In addition to the crews, there were "supervisors," trouble shooters, and the expected handful of straw bosses.

By 1:00 p.m., there was a lot of activity. The elevators had been repaired and were working. The supplies were on hand, and we were proceeding at full capacity. A pair of electric pallet movers and a forklift were used to load the freezer trucks. We had portable lights for working into the evening hours as well as a recharging station for the pallet movers. Once the basement telephone was reactivated by Pacific Telephone, this became the communication center.

Removing swollen books from the dozens of jammed shelves was occasionally a twoperson procedure with one on each side of the shelving unit. Because we had not acted soon enough, it required both pushing and pulling to remove the swollen materials from the jammed shelves. Some material was distinctly sticky. This obviously wet material was packed in boxes, spine down, single layer, with a sheet of freezer paper inserted between the volumes. Some materials, particularly smaller books, were completely wrapped with freezer paper (a step we later learned was not necessary). As we had some trouble producing sheets of freezer paper in cadence with the packing process, many items that were only slightly wet or apparently dry were packed with no freezer paper. Those items that had glued themselves together (particularly leather bindings) were gently separated where possible, an action that may have been a mistake.

As the books were packed, careful records of the first and last call numbers in each box were kept in order to maintain the callnumber sequence. Each box was numbered and recorded in a notebook-another effort that was later found to be unnecessary. This tabulation was, however, somewhat useful later in that it provided detailed information of what was removed.

Boxes, not being packed tightly, could be stacked only about four high, for fear they would collapse. And, of course, pallets could not be stacked upon each other. Thus, a truckload consisted of one layer of pallets. At the peak of activity on Sunday we had two large freezer trucks transporting pallets to the freezer. In retrospect, we probably could have used vans, or even open trucks, to transport the materials. The twenty to thirty minutes of cooling in a freezer truck probably added little to our success. The movement of pallets was economical of staff, but it was also a major 
Evidence of rapid swelling of the materials is clear. The books should be loosened before they hopelessly jam themselves onto the shelves.

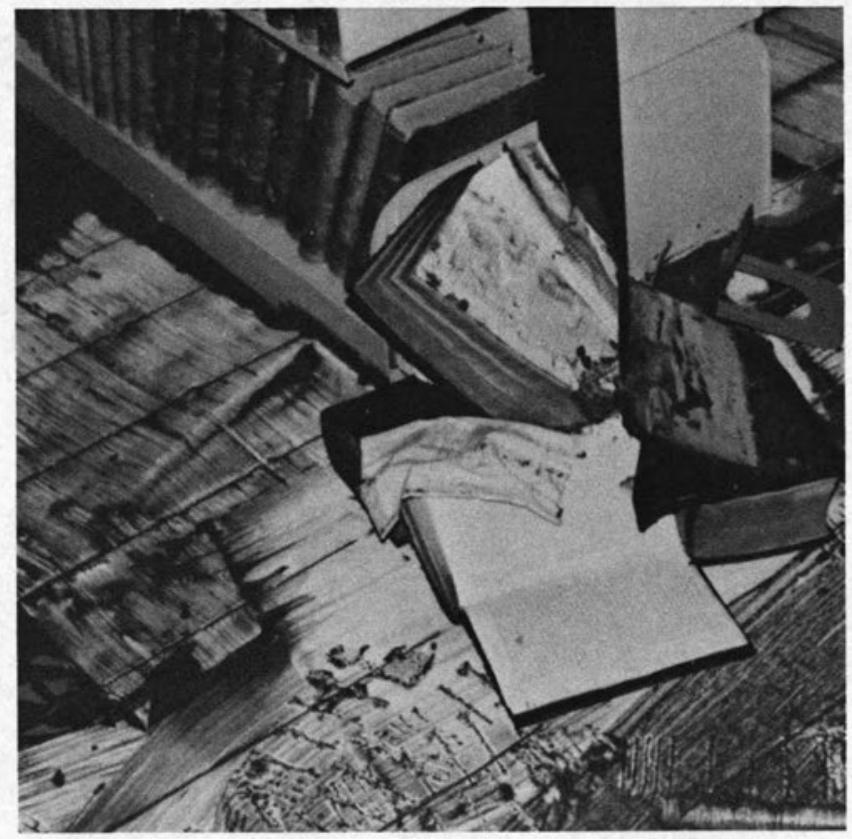

bottleneck in the process of moving boxes, suggesting perhaps the need for double equipment with two (or more) trucks being loaded simultaneously.

Even with the logistical problems and the time-consuming elements of learning how to cope, we were able to beat our deadline. A Saturday evening senior staff meeting was used to plan improved operations for the next day. All the materials were removed to the freezer by 9:00 on Sunday evening. About forty-two hours had elapsed from the first water until the final freezing. At minus twenty degrees Fahrenheit, the wet materials were quickly stabilized.

Humidity in the basement stacks dropped within an hour or two to less than 50 percent even though a substantial quantity of books remained. A hygrothermograph was set up to monitor the stability of the humidity, and spot checks were taken throughout the stack area with a sling psychrometer. It was interesting to note how little the humidity migrated within what is normally a dry stack. By the same token, the humidity would drop from 90 to 50 percent nearly as fast as the wet books were removed in the affected areas.
We now had time to plan for the next phase.

\section{MOP UP AND Plan Again}

Now that the pressure was off, our efforts were devoted to mop-up actions and detailed planning for the next phase. The remaining silt, which by then was dry, was removed from the floors of the Meyer basement, which remained closed for a week. Each emptied shelf was carefully cleaned with attention given to minimizing production of airborne dust. Because the humidity dropped so well, we elected not to fumigate the entire space for mold production, but rather to keep a close watch on the situation.

An informational memo was prepared for the Stanford community including information on the number of damaged materials and their specific subject areas. Philosophy was the area by far the most heavily affected, but there was also considerable damage to collections in religious studies and in the fields of Latin American, German, and Slavic and East European studies. ${ }^{5}$

Within the week following the accident, 


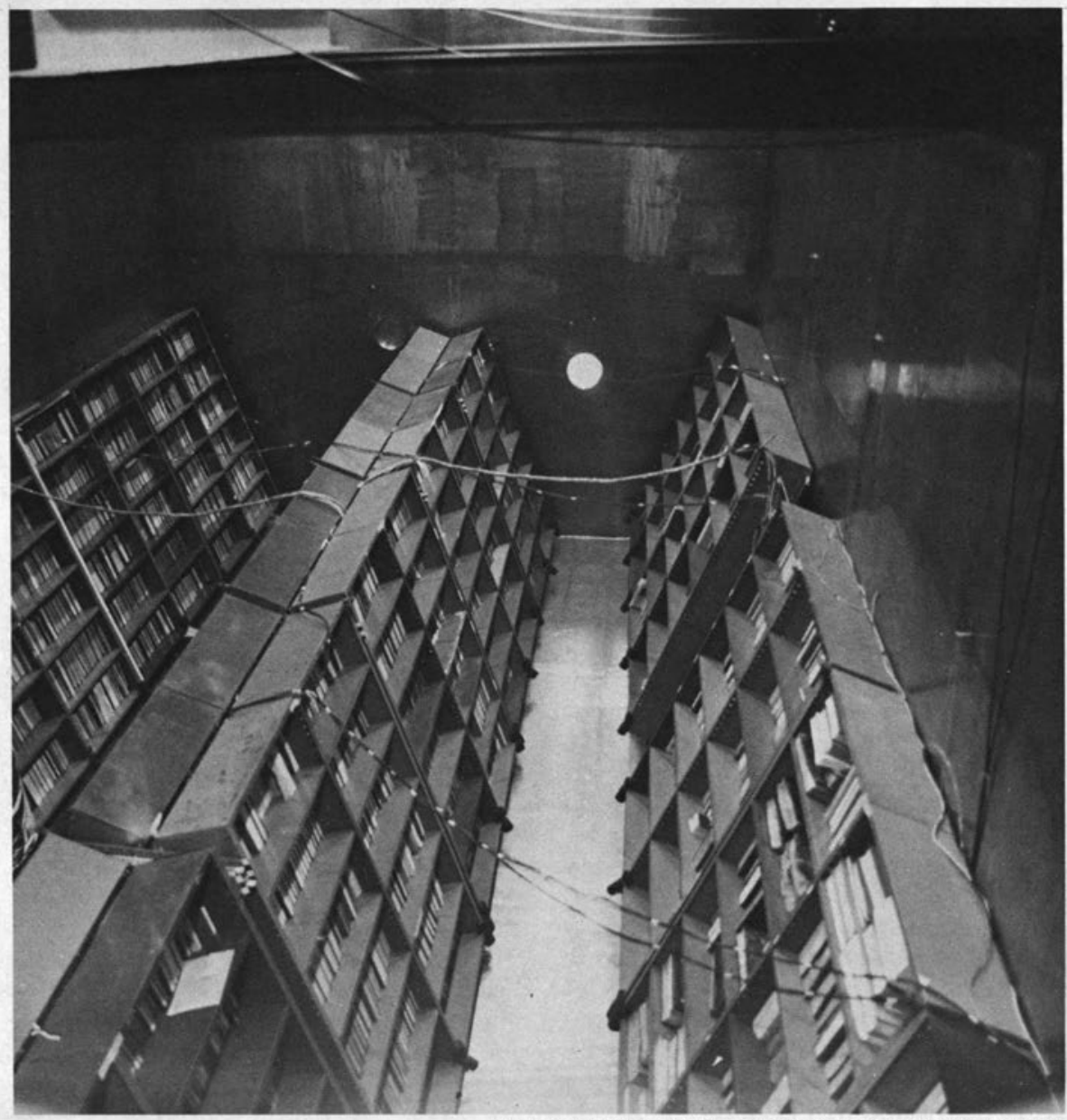

Courtesy of Lockheed Missiles \& Space Company, Sunnyvale, California

The Lockheed STARS Chamber, Sunnyvale, California. The shelving was installed at an angle to ensure that the books had maximum contact with the back of the shelving unit. Heater strips were mounted on the back panel with each section individually controlled.

as much material as possible was gathered from the literature covering flood restoration efforts since about $1970 .^{6}$ It was not long before we realized that vacuum- or freeze-drying was the preferred method. Both General Electric in Pennsylvania and McDonnell Douglas in St. Louis, Missouri, have used, with success, variations of the freeze- or vacuum-drying process. We also concluded that it would be useful to consult with Peter Waters at the Library of Congress, but before the first contact, two of the library staff would explore the freezedrying chambers in the region.

Typically, vacuum- or freeze-dry chambers are found associated with certain kinds of scientific research, the food-processing industry, and the aerospace industry. (Two small chambers used in research were located at Stanford, but neither of them was suitable for the library.)

A few odd chambers may be found, such as one brought to our attention that was being used by a taxidermist. Of the cham- 
bers visited locally, four seemed to hold some degree of real promise. In weighing factors of accessibility, flexibility, availability, and scale, we concluded that the best facility would be the Lockheed STARS chamber in Sunnyvale, California, situated about halfway between the library and the freezer facility.

It turned out that Lockheed has a considerable assortment of chambers. The one best suited for our anticipated drying process was directly accessible for truck deliveries, measured 18 feet by 18 feet by 36 feet long, was capable of very low pressures $\left(10^{-7}\right.$ torr $)$, had a flat floor so that shelving could easily be set up and was easily fitted with a liquid nitrogen cryopanel. It was also the chamber nearest to the freezer facility where the books were now stored. In short, it was ideal.

A major concern at this point was detailing specifications that would work and that could be used to develop cost estimates. We first started talking with Waters on November 15 on this topic and during several lengthy phone conversations discussed the following kinds of questions:

A. Should the materials be sorted in any way? We finally decided not to, largely because of the difficulty of working in a freezer; but factors of drying costs, sorting difficulty, uniformity of wetness, value of materials, replaceability of materials, degree of water damage to materials, etc., must be considered. There could easily be cases where sorting would be justified.

B. Should the materials be heated, and if yes, in what way and how much? Some heat must be applied to speed the drying process in the vacuum chamber. We concluded that the heat could be supplied by heater strips on shelving racks, a heat blanket, or heat lamps, although control, especially for the lamps, would be a critical factor. We preferred the concept of heater strips because of the ease of control. In any case, the ice must be sublimated, i.e., evaporated without melting.

C. Is there any danger in extreme vacuum of exploding the cellular structure of paper? As nearly as we could tell, if the materials were fully frozen, there was no particular hazard in this area. The books did not turn to powder, as one might expect.
D. Should we fumigate for mold? The literature recommends fumigating, ${ }^{7}$ and yet we were fairly confident that, because of the speed with which the materials were removed from the stacks and frozen, there should be little problem of developing mold. We concluded that, if we did not fumigate, the affected materials should not be replaced in the general stack area until they had undergone a four- to six-week period of observation. For several reasons, not the least of which was regard for the environment, we elected not to fumigate. As it turned out, Lockheed would not have been willing to do so in any event because of concern for their staff and the environment.

E. Could we overdry the books? Our feeling and that of our consultant, although this is really not scientifically substantiated, was that we could overdry the books, especially the binding glues. Because of this, we planned to open the chamber and remove dried books before the entire load was dry.

F. Should materials be removed from the boxes for drying? While there was great interest in leaving the materials boxed, especially for handling reasons, it was felt that the added difficulty in applying heat might be a major problem. It was agreed to try various methods in an experiment.

G. Should an experimental run be conducted? Because of the lack of specific detailed knowledge, it was felt that such a run, using materials of little or no value, should be done.

H. How low should the vacuum be taken? Once established, the vacuum should be maintained at four torr or lower. (Above four torr the ice no longer sublimates to water vapor, a critical aspect in the freezedrying process.) In our case, the vacuum was considerably lower than four torr. One suggestion was to evacuate to the lowest possible level and then back pressure with heated (one hundred degrees Fahrenheit) nitrogen or dry air. Based upon advice of the scientists at Lockheed, we elected not to do this.

I. What if we did not get the chamber loaded quickly enough and we did experience free water in the books? We felt that in this case, the vacuum should be brought down slowly to minimize the hazard of blistering. It was estimated that we had two to 
three hours to load the chamber once the materials left the freezer.

J. How would we know when the materials were dry? While there were several thoughts on how this might be established, the most effective method turned out to be a plotted graph of the temperature inside eighteen frozen books in which temperature probes had been implanted. As the dry state is reached, the temperature curve moves fairly quickly toward the temperature of the heater strips.

K. How long would it take to dry the books? Initial estimates were five to seven days within the vacuum chamber. It turned out that we could dry nearly all materials in half that time.

L. Should steam be used as a source of heat? Our consultants advised us not to.

M. Should materials be reacclimated? Yes, for as they come out of the drying chamber, they will be very brittle. They should be handled as little as possible for two to four weeks (the longer, the better) in an atmosphere of seventy degrees or less, 50 percent relative humidity. During this phase the materials should not be tightly packed.

During the course of early planning and operation of the drying process, the University Libraries employed Sally Buchanan as the special coordinator of the drying and restoration effort, which is presently under way. Her project is proceeding in a very encouraging way, and almost no material will be a total loss, even motion-picture film.

\section{CONCLUSION}

It is always useful to have a disaster plan. Key elements include a mechanism to ensure that responsible individuals are made aware of a disaster at the earliest possible time; previous contacts for critical supplies, equipment, or facilities; and a tabulation of immediately accessible sources of information. Fortunately, we had these three major elements. Beyond these basics, it is difficult at best to plan for a specific event. In our case, no one had any idea that a pipe outside the building would burst and flood the basement at nearly 3:00 a.m. And yet we coped.

A significant factor in our ability to cope came in the form of good will from staff, neighbors, and friends. To this day we are still benefiting from the generosity of superb gifts and the continuing work effort of volunteers. While we have a great deal to do yet, the final cost may be surprisingly low due to these fine efforts.

In retrospect, the following comments offer a few items to consider prior to or during the early stages of a flood.

1. Never store library materials on the floor of the lowest level of a building. In fact, it is a good idea to keep all materials off the floor. Just the four inches of the base shelf above the floor in standard shelving can make a world of difference.

2. Do have a sprinkler system. While it is true that this flood was caused by a sprinkler main line outside the building, we are still strongly of the opinion that the risk of no sprinkler system is greater than the risk with a sprinkler system. ${ }^{8}$

3. Install appropriate early-warning devices in significant stack areas. A water detector can be made with a sponge (the type that expands rapidly when wet), in contact with the floor and fitted within a box with a microswitch tied in to a central alarm system.

4. Ensure that the local authorities who might respond to an emergency have, and will use, a phone list of key persons in the organization.

5. Maintain a disaster file with all types of information including names and phone numbers of freezer facilities, paper suppliers, truck rental agencies, people who can help, etc. Contact some of these people to establish an understanding before disaster strikes. All senior library officials should have basic information at their homes.

6. Move quickly but with care. The first goal is to stabilize the environment and remove the wet materials to a freezer as soon as possible.

7. If concerned, consult an electrician prior to entering a flooded area. While the likelihood of shock is fairly low, there can be real hazards.

8. Open windows and doors, and turn on the ventilation system (without heat) as soon as possible to remove humid air. In some cases, it may even be worth breaking out some windows. The warmer and the more 
humid the environment, the faster the mold forms.

9. Work on the details before you muster a large work crew. You will probably need food, supplies, and certain equipment actually on hand or on the way before starting the real task. Establish who is responsible for what. Only two crews can work in a range aisle; a crew of three people is usually the maximum size.

10. Maintain a command post. We received a constant flow of calls once our event made the news. If nothing else, it is good public relations to respond to these calls. Occasionally, a truly useful bit of information may be received.

11. Do not jump into the "ideal" solution you may hear about. Consult experts before doing something new or untried; find out if you can why it has not been done before.

12. Unless you are moving materials over excessive distances, do not worry about a freezer truck. Of course, if one is available, it is useful, but it is more likely to be difficult to find one.

13. In a large disaster, use pallets, pallet movers, and forklifts. You can load trucks quickly without a loading dock by means of these devices.

14. Do not be overly concerned about numbering each box. For us it was a nearly total waste of time.

15. Don't wrap each book completely in freezer paper. For the wet items, single sheets of freezer paper between volumes are enough. Any book that is dry to the touch probably does not need any freezer paper unless it is packed with obviously wet books.

16. If possible, loosen the tightly packed books before they swell and jam themselves in so thoroughly on the shelves as to be nearly impossible to remove (ten hours maximum, in our case).

17. Have one person watch for logistical logjams. Often a little common sense or ingenuity can greatly improve the flow of materials.

18. When materials have fallen to the floor and are thereby badly distorted, try to straighten them out a bit. Do not worry too much about the binding; it is probably destroyed already. The text is what one wants to save, and flattening during packing can help greatly during restoration. Books frozen in distorted condition tend to remain distorted when dried.

19. If books stick together, they probably will come apart in the freeze-drying process. If they pull apart easily, fine; but otherwise they can be left stuck together.

20. Do not get too discouraged. At the worst, you will look back upon any such event as an "interesting" experience. On the positive side, the enthusiasm generated by staff and volunteers in the interest of helping is indeed rewarding. And, with hard work, a few basic utilities and facilities, and perhaps a little luck, you can save most of the material.

\section{REFERENCES}

1. William Spawn, "After the Water Comes," Pennsylvania Library Association Bulletin 28:243-51 (Nov. 1973), provides another look at the initial salvage operations following a flood. Quite by chance, Spawn's scenario involves a broken water main outside a basement storage facility.

2. The key guide to library rescue operations is Peter Waters, Procedures for Salvage of Water-damaged Library Materials (Washington, D.C.: Library of Congress, 1975). Not only should every library have this document, but its exact location also should be well known.

3. Comments confirming the concern about being flooded with assistance once the need is publicized may be found in Arthur T. Hamlin,
"First Considerations for the Flood Season," Wilson Library Bulletin 48:660-63 (April 1974).

4. An excellent discussion of the needs of disaster planning, especially for floods, is found in Hilda Bohem, Disaster Prevention and Disaster Preparedness (Berkeley: Office of the Assistant Vice-President-Library Plans and Policies, Systemwide Administration, Univ. of California, 1978).

5. David C. Weber, "The Nature of the Recent Water Damage to Research Collections," memo to the faculty and students of Stanford, Nov. 28, 1978.

6. Perhaps the most complete documentation of a recent flood is to be found in a booklet edited by John H. Martin, Museum under Water 
(Corning, N.Y.: Corning Museum of Glass, 1977). In this document the concepts of fumigation and freeze-drying (among others) are discussed in careful detail.

7. A number of sources speak of the benefits of fumigation. A particularly good article on freeze-drying and fumigation is Martin G. Koesterer and John A. Geating, "Application and Utilization of a Space Chamber for the
Drying of Books, Documents, and Other Materials and Their Decontamination to Prevent Biodeterioration," Journal of Environmental Sciences 19:29-33 (Sept. 1976).

8. The benefits of good fire-control systems are substantiated in John Morris, Managing the Library Fire Risk, 2d ed. (Berkeley: Univ. of California, 1979).

Editor's Note: The November 1979 issue of our Journal will feature Sally Buchanan's article, "The Stanford Library Restoration Project," which describes the drying of the damaged books in the vacuum chamber and their subsequent repair by a special project staff. 


\section{New1980 Guidesto Books on Demand}

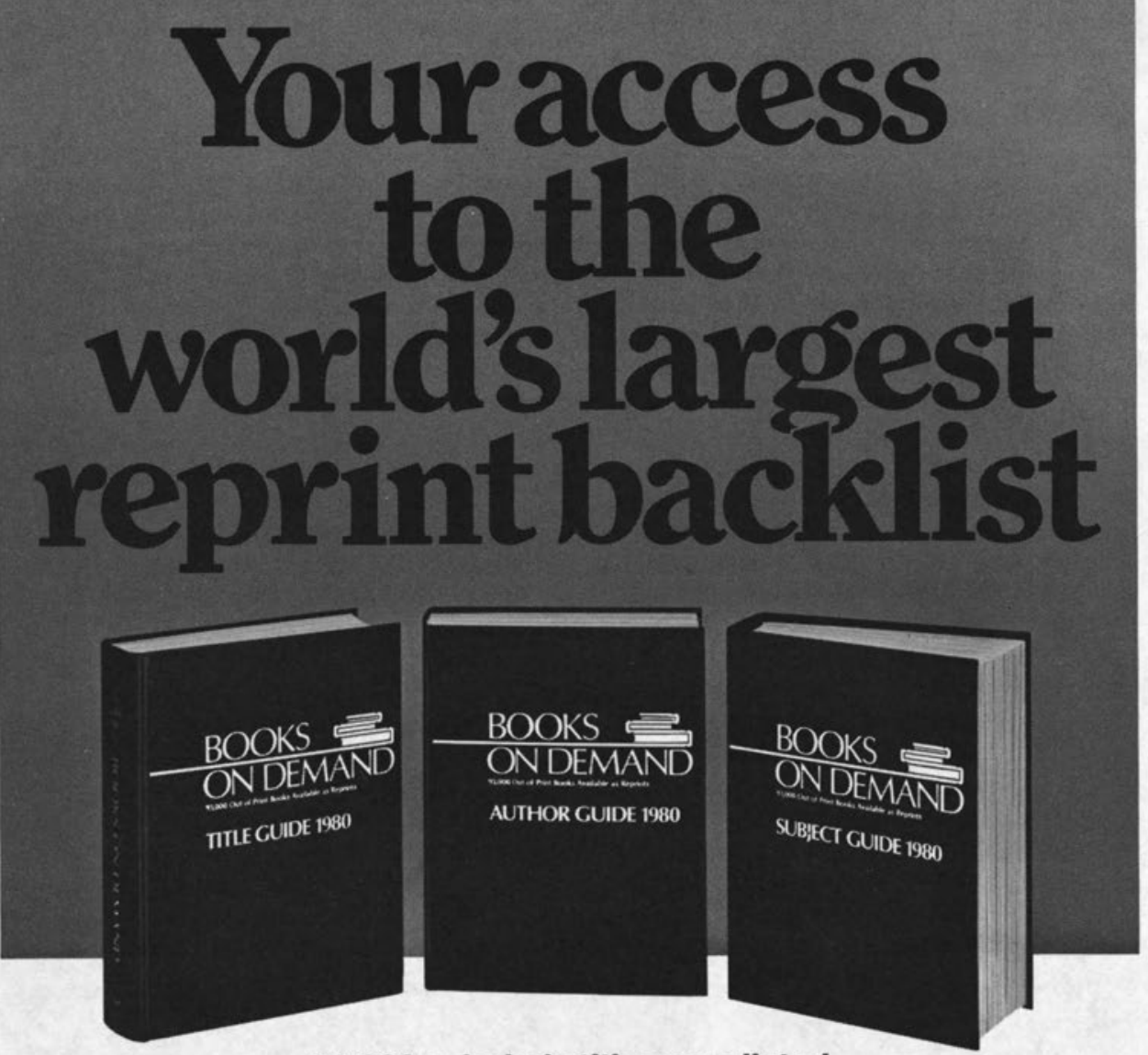

\section{3,000 scholarly titles now listed. \\ - 9000 OP titles from 300 publishers added since last edition.}

Use the updated Guides just like Books in Print. They are, said $\mathrm{LJ}$, "an essential purchase for any acquisitions department." When you phone in an order for any of our 93,000 OP titles your reprint will be custom produced on acid-free paper, bound in paper or cloth, and delivered within thirty days.

Save $9 \%$ on all three volumes. Order the complete set for just $\$ 73.50$. Individual Author, Title, and Subject Guides \$26.95 each.

Call in your order toll-free: 800-521-0600. 